\title{
Emerging Barrier to Timely Care of Hip Fracture Patients: A Prospective Study of Direct Oral Anticoagulation and Time to Surgery
}

Marlis T Sabo, Fatima Mahdi, Leanne Reimche, Marcia Clark

\section{About the Authors:}

Marlis T Sabo is a Clinical Assistant Professor, Department of Surgery, Cumming School of Medicine, University of Calgary, Calgary, Alberta. Fatima Mahdi is an MD Candidate, Cumming School of Medicine, University of Calgary, Calgary, Alberta. Leanne Reimche is a Clinical Assistant Professor, Division of General Internal Medicine, University of Calgary, Calgary, Alberta. Marcia Clark is a Clinical Associate Professor, Department of Surgery, Cumming School of Medicine, University of Calgary, Calgary, Alberta. Corresponding Author: marlis.sabo@gmail.com

Submitted: February 5, 2018. Accepted: June 10, 2018. Published: November 9, 2018. DOI: 10.22374/cjgim.v13i4.272

\begin{abstract}
Rapid surgical management of hip fracture patients is critical to reduce morbidity and mortality. These patients may be anticoagulated and the new direct oral anticoagulants (DOAC) may introduce delays to treatment. Our purpose was to examine the impact of these DOAC on time to surgical management for hip fracture patients.
\end{abstract}

\section{Methods}

A prospective audit of 55 consecutive operative hip fracture patients examined time from diagnosis to surgery. Indications for anticoagulation were recorded.

\section{Results}

Time to surgery for the DOAC group was $66 \pm 16$ hours, versus $38 \pm 21$ and $25 \pm 19$ hours for warfarin and control groups, respectively $(\mathrm{P}<0.05)$. Anticoagulation was for atrial fibrillation in $93 \%$.

\section{Conclusion}

Patients on DOAC faced significant delays to surgery. Given that both DOAC use and incidence of hip fracture are expected to rise, this presents a barrier to optimized care in this vulnerable group.

\section{RESUME}

La prise en charge chirurgicale rapide des patients fracturés de la hanche est essentielle pour réduire la morbidité et la mortalité. Ces patients peuvent être anticoagulés et les nouveaux anticoagulants oraux directs (DOAC) peuvent retarder le traitement. Notre objectif était d'examiner l'impact de ces DOAC sur le délai de prise en charge chirurgicale des patients souffrant d'une fracture de la hanche. 


\section{Méthodes}

Un audit prospectif de 55 patients consécutifs à une fracture de la hanche a examiné le temps écoulé entre le diagnostic et la chirurgie. Les indications pour l'anticoagulation ont été enregistrées.

\section{Résultats}

Le temps nécessaire à l'opération pour le groupe DOAC était de $66 \pm 16$ heures, contre $38 \pm 21$ et 25 \pm 19 heures pour la warfarine et les groupes témoins, respectivement $(\mathrm{p}<0,05)$. L'anticoagulation concernait la fibrillation auriculaire à $93 \%$.

\section{Conclusion}

Les patients sous DOAC ont dû faire face à des retards importants avant la chirurgie. Étant donné que l'utilisation de DOAC et l'incidence de fractures de la hanche devraient augmenter, cela constitue un obstacle à l'optimisation des soins dans ce groupe vulnérable.

Almost 30,000 elderly Canadians sustain a low-energy hip fracture each year. ${ }^{1}$ These injuries are common and are a major cause of morbidity and mortality. ${ }^{2,3}$ Early surgery reduces complications, length of hospital stay, facilitates return to independent living, and improves survival. ${ }^{4,5}$ The Canadian Institute for Health Information has a benchmark of 48 hours, ${ }^{6}$ while the UK National Health Service has a benchmark of 36 hours $^{3}$ from admission to surgery for these patients. The percentage of patients receiving surgery within 48 hours increased over time to $86 \%$ in $2016 .^{6}$ However, barriers to performing timely surgery continue, and the definition of "timely" continues to move earlier and earlier."

Among the more challenging barriers to early surgery remains the problem of anticoagulation. Previously, all patients would be anticoagulated with warfarin, which can be reversed with vitamin $\mathrm{K}$, fresh-frozen plasma, or Octoplex ${ }^{\circ}$. With the increasing use of direct oral anticoagulants (DOACs) the use of warfarin is slowly declining in favour of these other medications. ${ }^{8}$ This is further fuelled by consensus statements such as the Canadian Cardiology Society 2016 guidelines urging physicians to move their patients to DOAC from warfarin. ${ }^{9}$ While each DOAC has advantages, disadvantages, and individual pharmacological considerations, most are irreversible at this time (dabigatran has a specific antidote, idarucizumab, which is available in Canada).

The perioperative management of DOAC medications is controversial. Patients undergoing major orthopaedic surgery are considered to have high bleeding risk. ${ }^{8}$ The safe performance of surgery will depend on the surgeon, type of surgery, ${ }^{7}$ type of anaesthetic, ${ }^{7}$ the specific DOAC, and the patient's renal function. ${ }^{8}$ Perioperative management of DOAC for elective surgery is mapped out, ${ }^{8,10-15}$ but confusion exists regarding management in emergent situations.

Our purpose was to determine the time from radiographic diagnosis to procedure start time for hip fracture patients on DOAC compared with those on warfarin or on no anticoagulation.
We hypothesize that patients on any form of anticoagulants will face significant delays to surgery, but that those on DOAC will wait longest.

\section{Methods}

All patients presenting to our institution during the study period with a low-energy surgically-treated hip fracture were included prospectively from January - March 2017. Time from diagnosis to surgery was defined as the number of hours from the time stamp on the initial radiographs to the procedure start time from the official OR record. Demographic data, important comorbidities, indications for anticoagulation and its dosing, INR (international normalized ratio), GFR (glomerular filtration rate), type of surgery and type of anaesthesia were recorded for each patient.

A difference of 24 hours in time to surgery was felt to be the minimum clinically important difference (MCID). Based on data from a pilot retrospective audit and this MCID, a minimum of three patients in each group provided $80 \%$ power to detect a 24-hour difference. Data was collected for 3 consecutive months to ensure that we achieved this sample size, and also obtained enough information to draw conclusions about our secondary outcomes.

Statistical analysis of the demographic data (descriptive statistics) and comparison between groups was performed (one-way ANOVA). Data was not adjusted for other medical, non-medical, or non-surgical delays, and the single patient on clopidogrel was excluded from intergroup comparisons. Ethics approval was sought and obtained from the local research ethics board (REB 16-1324).

\section{Results}

A total of 55 patients, 41 females and 14 males with average age $79.3 \pm 12.9$ years were included. A total of $14(25 \%)$ were taking 
Table 1: Demographic Data and Preoperative Laboratory Values

\begin{tabular}{|l|c|c|c|c|}
\hline $\begin{array}{l}\text { Demographic } \\
\text { (Mean) }\end{array}$ & $\begin{array}{c}\text { No Anticoagulants } \\
{[\mathbf{n = 4 1 ]}}\end{array}$ & $\begin{array}{c}\text { Warfarin } \\
{[\mathbf{n = 8}]}\end{array}$ & $\begin{array}{c}\text { Apixaban } \\
{[\mathbf{n = 5}}\end{array}$ & $\begin{array}{c}\text { Total } \\
{[\mathbf{n}=\mathbf{5 5}]}\end{array}$ \\
\hline Age & $77.3 \pm 14.0$ & $84.5 \pm 5.8$ & $87.2 \pm 7.4$ & $79.3 \pm 12.9$ \\
\hline Gender & $30 \mathrm{~F}$ & $7 \mathrm{~F}$ & $4 \mathrm{~F}$ & $41 \mathrm{~F}$ \\
& $11 \mathrm{M}$ & $1 \mathrm{M}$ & $1 \mathrm{M}$ & $14 \mathrm{M}$ \\
\hline Patients with Dementia & 17 & 4 & 2 & 23 \\
\hline GFR & $79.3 \pm 20.2$ & $57.5 \pm 21.1^{* *}$ & $61.0 \pm 18.1$ & $74.7 \pm 21.6$ \\
(>60 is normal) & & & & \\
\hline Serum creatinine & $71.3 \pm 37.4$ & $88.6 \pm 24.0$ & $83.8 \pm 19.1$ & $74.6 \pm 34.5$ \\
\hline Anaesthetic type & $13 \mathrm{GA}$ & $1 \mathrm{GA}$ & $2 \mathrm{GA}$ & $16 \mathrm{GA}$ \\
& 27 Spinal & 7 Spinal & 2 Spinal & 36 Spinal \\
\hline INR at admission & 1 Epidural & & 1 Epidural & 2 Epidural \\
\hline INR at Surgery & $1.08 \pm 0.1$ & $2.4 \pm 0.7^{*}$ & $1.4 \pm 0.2$ & $1.3 \pm 0.55$ \\
\hline
\end{tabular}

GFR = glomerular filtration rate; GA = general anaesthesia; INR = international normalized ratio.

*Denotes statistical significance $P<0.05$. * Denotes difference between warfarin and no anticoagulant groups $(P<0.05)$.

No patient in any group had a GFR $<30$. The 1 patient on Plavix is reflected in the Total $(n=55)$ column only.

either warfarin (8), apixaban (5), or clopidogrel (1). (While not strictly an anticoagulant, Plavix ${ }^{\oplus}$ use can also introduce delays to surgery.) There was no significant demographic difference between the three groups (Table 1). The warfarin group had a significantly higher admission INR $(\mathrm{P}<0.0001)$.

Distribution of fractures types showed $47 \%$ had a neck of femur fracture, $44 \%$ were had an intertrochanteric fracture, and $9 \%$ had a subtrochanteric fracture. The type of procedures performed for these fractures is shown in Table 2. The most common procedures were cephalomedullary devices and hemiarthroplasties.

Time to surgery for patients on apixaban was $66 \pm 16$ hours, longer than those on warfarin ( $38 \pm 21$ hours) and those not anticoagulated $(25 \pm 19$ hours $)(\mathrm{P}<0.05)$. Four of the eight patients

Table 2: Distribution of Types of Surgery

\begin{tabular}{|l|c|}
\hline Type of Surgery & Number of Patients (\%) \\
\hline Intramedullary Nail & $30(55)$ \\
Short & 21 \\
Long & 9 \\
\hline Hemiarthroplasty & $15(27)$ \\
\hline Total Hip Arthroplasty & $4(7)$ \\
\hline Internal Fixation & $6(11)$ \\
Cannulated Screws & 3 \\
Cannulated Screws + Dynamic & 3 \\
\hline Hip Screw & $55(100)$ \\
\hline Total
\end{tabular}

on warfarin were chemically reversed using Octoplex ${ }^{\oplus}$ with a mean time to surgery of $36.6 \pm 12.7$, while all warfarin patients received vitamin $\mathrm{K}$ pre-operatively. Use of Octoplex ${ }^{\otimes}$ was at surgeon discretion. No patient in either anticoagulated group faced delays for any medical reason beyond the time required to correct their anticoagulation.

Indication for anticoagulation was atrial fibrillation (93\%), or valve disease (7\%). The apixaban was used within FDA guidelines in 4 of 5 patients, and the last patient could not be confirmed due to inability to achieve an accurate pre-operative weight.

\section{Discussion}

Nearly one-quarter of the study population presented on anticoagulants, with the $9 \%$ on DOAC experiencing a substantial delay to surgery compared to the other groups. Four patients on warfarin were chemically reversed using Octoplex ${ }^{\oplus}$, potentially reducing the delays faced by the warfarin group. The delays observed in the warfarin and DOAC groups are consistent with previous reports from other studies. ${ }^{17}$ Patients on warfarin experienced delays to surgery despite the availability of a rapid antidote, similar to other studies. ${ }^{3,18,19}$ Waiting for INR normalization can cause delays without reducing the risk of bleeding or other complications. ${ }^{17}$ In this cohort, initiation of Octoplex ${ }^{\oplus}$ was associated with failure of INR to correct within 48 hours using vitamin $\mathrm{K}$ alone. Although the clinical need for anticoagulation could be viewed as a marker of greater medical comorbidity, this did not appear to add further medical delays to treatment in this cohort. 
The incidence of patients with operative hip fractures on DOAC in this cohort was $9 \%$, which is higher than earlier reports of $1 \%,{ }^{17}$ reflective of increased adoption of guidelines advocating a switch from warfarin to a DOAC. It is reasonable to conclude that DOAC use will overtake that of warfarin, making the problem of DOAC and emergent surgery more pressing in the future.

As the number of hip fracture patients on DOAC increases, important differences in care delivery may be encountered. Large cohort studies demonstrate that mortality in hip fracture patients starts to rise after 24 hours from time to diagnosis to surgical treatment. Pilot data from an ongoing multicenter trial suggests that mortality can be decreased by even more rapid surgery (within 6 hours of presentation). ${ }^{20}$ An antidote is available for only one DOAC (dabigatran) currently, but was not available at the time of this audit. While other antidotes will eventually become available, an already vulnerable population is exposed to increased risk of death due to hip fracture in the meantime. Based on the Thrombosis Canada guidelines for apixaban, $34 \%$ of this cohort would have "high bleeding risk" surgery, requiring 3 days delay, while the remaining $66 \%$ had "moderate bleeding risk" surgery, and could have been operated after 2 days. ${ }^{15}$ It is not clear at this time what the optimal balance of risk of surgical delay versus risk of proceeding in the face of active and irreversible anticoagulation is.

Selection of a minimum clinically important difference of 24 hours was influenced by the metrics already collected in the local health region. The smallest unit recorded for length of stay is a day. A clinically important effect size must be larger than the normal ebb and flow of patients and operating room access. Interestingly, unlike the Tran study, ${ }^{17}$ capacity issues were not a prominent problem in this cohort. While the data was not corrected for non-medical or non-surgical delays, few patients were affected by such delays. The vast majority of patients were treated in a priority fashion as operating theatre access allowed.

This is a small prospective cohort study, but it has some strengths. Because it was performed at a single site over a short period of time, it avoids heterogeneity arising from different operating theatre access and different practice patterns. There was sufficient power to address our primary outcome, but sweeping conclusions about our secondary outcomes are not possible. Furthermore, this audit was not designed to examine longer-term end-points such as complications, survival, or length of stay between groups.

In summary, patients on DOAC faced clinically significant delays to surgery in this prospective cohort. Nine percent of this cohort was on a DOAC, a higher prevalence than prior reports. Future work will need to relate the observed delays to patient outcomes, as well as assessment of the economic impact of these agents, especially in a time of health spending constraints. Given that DOAC are here to stay, evidence-based guidelines on management of these medications in a context in which even a 2-day delay may adverse affect patient survival will be of tremendous value to patients and their surgeons going forward. Collaboration between internists, anesthetists and surgeons will be vital to achieving this.

\section{References}

1. Tarride JE, Hopkins, RB, Leslie, W D, Morin, S, Adachi, JD, Papaionnou, A, Bessette, L, Brown, J P, Goeree, R. The burden of illness of osteoporosis in Canada. Osteo Internat 2012;23:2591-600.

2. Moran CG, Wenn, RT, Sikand, M, Taylor, AM. Early mortality after hip fracture: is delay before surgery important? J Bone Joint Surg Amer 2005;87-A(3):483-9.

3. Eardley WGP, Macleod, KE, Freeman H, Tate A. Tiers of delay: warfarin, hip fractures, and target-driven care. Geriatr Orthopaed Surg Rehabil 2014;5(3):103-8.

4. Zuckerman JD, Skovron ML, Kova KJ, et al. Postoperative complications and mortality associated with operative delay in older patients who have a fracture of the hip. J Bone Joint Surg Amer 1995;77-A(10):1551-6.

5. Al-Ani AN, Samuelsson RN, Tidermark J, et al. Early operation on patients with a hip fracture improved the ability to return to independent living. J Bone Joint Surg Amer 2008;90-A(7):1436-42.

6. CIHI. Hip Fracture Repair: Canadian Institue for Health Information; 2016. Available at: Available from: http://waittimes.cihi.ca/All/fracture.

7. Pincus D, Ravi B, Wasserstein D, et al. Association between wait time and 30-day mortality in adults undergoing hip fracture surgery. JAMA. 2017;318(20):1994-2003.

8. Spyropoulos AC, Al-Badri A, Sherwood MW, et al. J Thromb Haemost 2016;14:875-85.

9. Macle L, et al. 2016 Focused Update of the Canadian Cardiovascular Society Guidelines for the Management of Atrial Fibrillation. Can J Cardiol 2016;32(10):1170-85.

10. Massicotte A. A practice tool for the new oral anticoagulants. Can Pharm J 2013;147(1):25-32.

11. Xarelto Product Monograph. Mississauga, ON: Bayer Inc; 2016.

12. Pradaxa Product Monograph. Burlington, ON,: Boehringer Ingelheim Canada; 2016.

13. Apixaban Product Monograph. Kirkland, QC: Pfizer Canada Inc; 2015.

14. Perioperative Anticoagulant Management Algorithm. Thrombosis Canada; 2017.

15. NOACS/DOACS Peri-Operative Management. Thrombosis Canada; 2017.

16. Spyropoulos AC, Douketis JD. How I treat anticoagulated patients undergoing an elective procedure or surgery. Blood 2012;120(15):2954-62.

17. Tran T, Delluc, A, de Wit, C, Petrcich W et al. The impact of oral anticoagulation on time to surgery in patients hospitalized with hip fracture. Thrombosis Research 2015;136:962-5.

18. Cohn MR, Levack AE, Trivedi NN, et al. The hip fracture patient on warfarin: evaluating blood loss and time to surgery. J Orthop Trauma 2017;31(8):407-13.

19. Lawrence JE, Fountain DM, Cundall-Curry DJ, Carrothers AD. Do patients taking warfarin experience delays to theatre, longer hospital stay, and poorer survival after hip fracture? Clin Orthop Relat Res 2016;475:273-9.

20. The Hip Fracture Accelerated Surgical Treatment and Care Track Investigators. Accelerated care versus standard care among patients with hip fracture: the HIP ATTACK pilot trial. Can Med Assoc J 2014;186(1):E52-E60. 